REVISTA X, Curitiba, volume 13, n.2,p.34-46, 2018.

\title{
O USO DOS GÊNEROS ORAIS EM PRÁTICAS DE LETRAMENTO NA AULA DE LÍNGUA PORTUGUESA: ENCAMINHAMENTOS PARA A REFLEXÃO
}

The use of oral genres in literacy practices in the Portuguese language class: referrals to reflection

Silvio Nunes da SILVA JÚNIOR (UFAL) ${ }^{1}$

RESUMO: A partir das questões emergentes que vêm surgindo no todo social, diversas inquietações pertinentes em relação ao ensino e a aprendizagem de línguas estão aparecendo no campo da Linguística Aplicada (LA), uma delas, a que deu origem a este estudo, é sobre o uso da oralidade em sala de aula, e, mais a fundo, sobre a questão do letramento nas atividades didáticas em sala de aula no intuito de contribuir para o desenvolvimento do aluno para além dos muros da escola. Diante disso, proponho discutir acerca das atividades de letramento no ensino de língua portuguesa com a utilização dos gêneros debate e conto como meio de para contribuir para as práticas linguístico-discursivas dos alunos em situações de aprendizagem, e, além, disso, para o senso crítico deles. Ancoro-me nos estudos dialógicos de Bakhtin (2003) e Volochinov (2017) para refletir sobre os gêneros do discurso, nos estudos de letramento e, também, sobre ensino de língua portuguesa. Com base nessas leituras, aponto dois encaminhamentos, frutos de experiências próprias, de utilização dos referidos gêneros em aulas de língua portuguesa na educação básica.

PALAVRAS-CHAVE: Práticas Linguístico-discursivas; Letramento; Senso Crítico.

ABSTRACT: From the emerging issues that have arisen in the social whole, several pertinent concerns regarding language teaching and learning are appearing in the field of Applied Linguistics (LA), one of which gave rise to this study is about the use orally, in the classroom, and, furthermore, on the question of literacy in the didactic activities in the classroom in order to contribute to the development of the student beyond the walls of the school. Therefore, I propose to discuss literacy activities in Portuguese language teaching with the use of the genres debate and story as a means to contribute to the linguistic-discursive practices of students in learning situations, and, moreover, to the sense critical of them. I am anchored in the dialogical studies of Bakhtin (2003) and Volochinov (2017) to reflect on the genres of discourse, in literacy studies, and also on Portuguese language teaching. Based on these readings, I point out two referrals, the fruits of my own experiences, of using these genres in Portuguese language classes in basic education.

KEYWORDS: Linguistic-discursive practices; Literacy; Critical sense.

\footnotetext{
${ }^{1}$ Mestrando em Linguística pelo Programa de Pós-Graduação em Letras e Linguística da Universidade Federal de Alagoas (PPGLL/UFAL). Bolsista CAPES. Membro do Grupo de Pesquisa Ensino e Aprendizagem de Línguas (CNPq/UFAL) e do Grupo de Estudo das Narrativas Alagoanas - GENA (CNPq/UNEAL). E-mail: junnyornunes@ hotmail.com
} 
REVISTA X, Curitiba, volume 13, n.2,p.34-46, 2018.

\section{CONSIDERAÇÕES INICIAIS}

"Fessô, vou ali, venho já!". Enunciados como este vêm me inquietando desde 2015, quando iniciei as minhas experiências enquanto estagiário de Língua Portuguesa ${ }^{2}$, ainda na graduação em Letras. As inquietações surgiam principalmente pela visível reação de muitos professores ao ouvirem variações linguísticas como a que está destacada, onde automaticamente dizem que falar assim é errado e feio, isso em tom de fúria, em muitas das vezes.

Após cursar disciplinas que abordavam as variações linguísticas (com maior ênfase a sociolinguística) percebi que todas as manifestações de linguagem dos alunos deveriam ter finalidades didáticas em sala de aula, pois é nela que os saberes se intercalam e constituem a aprendizagem significativa, que, de modo algum, deve ser construída por 'reproduções de conteúdos', , mas sim, por múltiplas práticas que levem o aluno a assumir uma postura crítica e reflexiva.

Nesse sentido, desenvolvi a minha monografia de conclusão de curso querendo entender se os professores de língua portuguesa da atualidade realmente acreditam que o ensino de gramática é o único veículo para aprender a língua materna (POSSENTI, 1996) ou se creem num ensino mais pautado nas práticas de ensino de língua portuguesa que atravessem os muros da escola e contribuam para a formação cidadã. Com o estudo, conclui que os professores veem a necessidade de se ensinar a gramática, no entanto, percebem que um ensino pautado somente nela não traz resultados satisfatórios.

Nessa perspectiva, as inquietações não paravam por aí: também existia a vontade de saber o porquê de os professores valorizarem tanto a modalidade escrita da língua, deixando a oralidade para poucos momentos ou, até mesmo, sem valor algum. Foi isso que me trouxe para a pesquisa que venho desenvolvendo no Programa de PósGraduação em Letras e Linguística da Universidade Federal de Alagoas (PPGLL/UFAL), no curso de mestrado em Linguística Aplicada, com o tema $O$ trabalho colaborativo no ensino de língua portuguesa com os gêneros orais em práticas de letramento.

Corroborando com Bakhtin (2006), na concepção de que a linguagem se estabelece como um aspecto social concreto e dinâmico, vejo que a oralidade pode contribuir em grande escala para as práticas linguístico-discursivas e o senso crítico dos

\footnotetext{
${ }^{2}$ No ensino fundamental e médio de escolas de esfera pública do interior de Alagoas.

${ }^{3}$ Lembro, aqui, da pedagogia tradicionalista e, em sentido mais restrito ao ensino de língua portuguesa, o ensino totalmente voltado às regras normativas da gramática.
} 
REVISTA X, Curitiba, volume 13, n.2,p.34-46, 2018.

alunos; além de observar a concepção sociointeracionista que os Parâmetros Curriculares Nacionais de Língua Portuguesa apontam para o ensino, onde se enquadram com grande importância os gêneros orais. Acrescento também que o ensino, até onde for possível, precisa se enquadrar nos contextos sociais em que os alunos se inserem como bem lembram os estudos sobre letramento, pois é na valorização dos saberes locais que muitos alunos sentem-se úteis para contribuir com as aulas, as quais se tornam em grande escala mais atrativas.

Pensando assim, proponho, com esse estudo, refletir sobre os gêneros do discurso oral em aulas de língua portuguesa na educação básica., na tentativa de subsidiar teórico-metodologicamente as práticas pedagógicas de professores de língua portuguesa em serviço e pré-serviço. A fundamentação teórica abarca teorias da Linguística Textual para iniciar as noções de texto e modalidades de linguagem, seguindo com uma breve abordagem sobre o pensamento bakhtiniano sobre os gêneros do discurso; em seguida, discuto sobre o ensino de língua portuguesa com base nos gêneros orais a partir das de letramento, para então trazer dois encaminhamentos, frutos de minha experiência como docente, para o trabalho com os gêneros debate e conto em sala de aula.

\section{TEXTO, DISCURSO, GÊNERO E ENSINO}

As produções enunciativas em situações de ensino e de aprendizagem nas aulas de língua materna são pontos que merecem destaque, pois são partes constituintes das formações de alunos como sujeitos responsivos ativos ${ }^{4}$ capazes de contribuir criticamente para o avanço social que tanto estimamos, principalmente quando os olhares são para a educação escolar brasileira. Partindo de uma noção pautada na Linguística Textual (LT), observo a expansão de duas modalidades de linguagem que, quando o assunto é o ensino, são de incontestável importância para as práticas linguístico-discursivas dos alunos: a oralidade e a escrita (MARCUSCHI \& DIONÍSIO, 2007). Sob esse viés, inter-relaciono essa importância com a minha prática pedagógica enquanto professor regente de turmas de ensino fundamental e cursos profissionalizantes, bem como às experiências como estagiário na época da graduação.

\footnotetext{
${ }^{4}$ Refiro-me a de atitude responsiva ativa, encontrada na noção de responsividade em Bakhtin (2003), onde também se encontra a compreensão responsiva ativa e as possibilidades de compreensão do que é o sujeito responsivo ativo. Nesse sentido, "toda compreensão da fala viva, do enunciado vivo é de natureza ativamente responsiva (embora o grau desse ativismo seja bastante diverso); toda compreensão é prenhe
} 
REVISTA X, Curitiba, volume 13, n.2,p.34-46, 2018.

Com as minhas pesquisas situadas na transdisciplinaridade da LA (MOITA LOPES, 2006), tentarei estabelecer, nesse tópico, um diálogo entre os estudos textuais sobre as modalidades de linguagem com a noção de gênero do discurso em perspectiva dialógica (a que venho tomando como base há algum tempo), uma vez sendo salutar partir das modalidades de linguagem para chegar onde quero com esse estudo.

Sabendo que o estudo da língua se funda em usos (MARCUSCHI, 2001), entendo que ambas as modalidades de linguagem, por essência, já se constituem enquanto práticas sociais, como Marcuschi (2001) também alerta. Na mesma vertente de pensamento, Koch (2005, p.78) apresenta, na tabela abaixo, as principais diferenças entre oralidade/fala e escrita:

\begin{tabular}{|c|c|}
\hline Fala & Escrita \\
\hline $\begin{array}{l}\text { Contextualizada } \\
\text { Implícita } \\
\text { Redundante } \\
\text { Não-planejada } \\
\text { Predominância do 'modus pragmático' } \\
\text { Fragmentada } \\
\text { Incompleta } \\
\text { Pouco elaborada } \\
\text { Pouca densidade informacional } \\
\text { Predominância de frases curtas, simples ou } \\
\text { coordenadas } \\
\text { Pequena frequência de passivas } \\
\text { Pouca nominalização } \\
\text { Menor densidade lexical }\end{array}$ & $\begin{array}{l}\text { Descontextualizada } \\
\text { Explícita } \\
\text { Condensada } \\
\text { Planejada } \\
\text { Predominância do 'modus sintático' } \\
\text { Não fragmentada } \\
\text { Completa } \\
\text { Elaborada } \\
\text { Densidade informacional } \\
\text { Predominância de frases completas com } \\
\text { subordinação abundante } \\
\text { Emprego frequente de passivas } \\
\text { Abundância de nominalizações } \\
\text { Maior densidade lexical }\end{array}$ \\
\hline
\end{tabular}

Fonte: $\mathrm{KOCH}(2005, \mathrm{p} .78)$

Observando as diferenças entre uma modalidade da outra, vejo que mesmo com tamanhas convergências na produção enunciativa nas atividades de linguagem, uma sempre vem em muitas circunstâncias acompanhando a outra. Dessa forma, tomando como exemplo fictício uma situação de palestra em ambiente acadêmico pode-se ter essa constatação prévia:

Mestre de Cerimônia: Após a explanação das reflexões sobre os avanços na formação de professores no século XXI, a prestigiada Profa. Dra. Lúcia Albuquerque inicia, agora, o momento para debater quaisquer questões que surgirem na plateia. Quem se candidata? 
REVIST A X, Curitiba, volume 13, n.2,p.34-46, 2018.

$\mathrm{AG1}^{5}$ : _ Eu queria perguntar uma coisa que não ficou muito bem esclarecida...

AG26: __ Pergunta, ué!

AG1:__ Tenho medo de gaguejar, de falar informalmente diante do público!

AG2: __ Ah, é verdade! Então escreva antes de perguntar. Daí você se situa!

AG1:__Legal! Vou escrever!

(Após ler e reler o texto escrito) __ Olá, professora, boa tarde. Gostaria de saber se em um estudo sobre as práticas reflexivas num projeto de pesquisa posso utilizar as teorias de Alarcão e Zeichner sem nenhum problema ou divergência teórica com as que a senhora mencionou.

Com essa pequena exemplificação é possível perceber o quão é natural relacionarmos a oralidade com a escrita, sempre em busca de uma produção de sentidos mais eficiente para nós (locutores) e os outros (interlocutores), onde, sem dúvidas, a linguagem se estabelece enquanto aspecto social, concreto e dinâmico, como lembra Bakhtin (2003, p. 80):

Todas as esferas da atividade humana, por mais variadas que sejam, estão sempre relacionadas com a utilização da língua. Não é de surpreender que o caráter e os modos dessa utilização sejam tão variados como as próprias esferas da atividade humana, o que não contradiz a unidade nacional de uma língua. A utilização da língua efetua-se em forma de enunciados (orais e escritos), concretos e únicos, que emanam dos integrantes duma ou doutra esfera da atividade humana.

Nos discursos que circulam no dia-a-dia, tanto na interação presencial como a distância, e até mesmo pelos diversos veículos de informação, percebe-se uma gama de situações diversificadas no tocante ao uso da linguagem. Os enunciados, mesmo quando não se contradizem, nunca são iguais, mas possuem uma unicidade explícita. O que os deixam únicos é, justamente, as situações onde são pronunciados, pois na pronuncia/voz podemos identificar as intenções que o outro tem ao produzir discursivamente por meio de três elementos, a saber: "conteúdo temático, estilo e construção composicional” (op. cit). É ao perceber essas questões nas atividades de linguagem que trago a noção de gênero do discurso como "qualquer enunciado considerado isoladamente é, claro,

2003, p. 271).

${ }^{5}$ Aluno de graduação 1.

${ }^{6}$ Aluno de graduação 2. 
REVISTA X, Curitiba, volume 13, n.2,p.34-46, 2018.

individual, mas cada esfera de utilização da língua elabora seus tipos relativamente estáveis de enunciados" (op. cit).

Nessa perspectiva, é inviável que pensemos nas práticas de linguagem sem que sejam enfatizados os gêneros do discurso, uma vez que eles são os elementos que constituem cada uma das nossas atividades, tanto na oralidade como na escrita.

Levar essa discussão para a prática de professores de língua portuguesa em serviço, a meu ver, pode servir como uma fonte inesgotável de conhecimento para aprimorar a prática pedagógica, justamente pela importante relação entre oralidade e escrita que pode ser expandida juntamente aos alunos, o que, infelizmente, não vem sendo visto com frequência nas salas de aula. Digo isso tanto na esfera pública como na privada.

É factível que a tarefa do professor de língua portuguesa é desafiadora pela obrigatoriedade do ensino gramatical e da produção textual. No entanto, é nesse termo "textual" que encontro o meu foco com a seguinte questão: Qual a concepção de texto dos professores?

Não é meu intuito, aqui, discutir sobre as concepções de texto de professores em serviço, nem tampouco insinuar que estes sejam leigos no que concernem as teorias que mediam as suas práticas de ensino. Porém, com tudo o que venho observando, a falta de formação continuada e sobrecarga de trabalho compromete, e muito, a prática de professores que têm, creio eu, potenciais que podem contribuir para alavancar a qualidade do ensino de língua portuguesa e outras línguas.

Segundo os Parâmetros Curriculares Nacionais da Língua Portuguesa, os alunos terão o aproveitamento necessário da educação básica se saírem da escola com uma competência discursiva, a qual, no próprio documento, caracteriza-se pela capacidade de produzir discursos - orais e escritos - desde que estejam situados em contextos enunciativos, dando importância, também, aos aspectos e decisões envolvidos nesse processo (BRASIL, 1998). Com base nisso, o documento atribui à escola a obrigatoriedade de dar conta de tal competência na formação do aluno. Entretanto, é deixado de lado o conhecimento com o qual o aluno adensa na escola que, sem dúvidas, é discursivo.

Diante da noção presente nos PCN, não posso, como professor, e em preparação para a atuação como formador de professores, afirmar que é de obrigação dos professores em serviço irem atrás de formação, isso por observar que: 
[...] numa época em que o professor é mais do que nunca exigido em termos de atualização de conhecimentos acadêmicos e de produção (escrita, principalmente), ao mesmo tempo se vê com seu tempo limitado para investir em leituras que aprofundem e atualizem seus conhecimentos (ZOZZOLI, 2010, p. 128).

Dentro de minhas possibilidades enquanto sujeito em constante processo de formação e constituição de saberes, entendo que para os professores inovarem ou adequarem as suas práticas ao que a sociedade delega, é necessário que reflitamos junto a eles em momentos de coleta de dados para pesquisa e com a divulgação de estudos científicos os modos de aprimorar a prática de ensino. Com isso, proponho, no tópico seguinte, discutir brevemente sobre os gêneros orais em aulas de língua portuguesa com as práticas de letramento, e, posteriormente, apresentar dois encaminhamentos de atividades de inter-relação de oralidade e escrita na sala de aula de língua portuguesa.

\section{GÊNEROS ORAIS E SUAS RELAÇÕES COM AS PRÁTICAS DE LETRAMENTO}

As discussões deste tópico focalizaram nas relações entre o trabalho com a oralidade em sala de aula nas chamadas práticas de letramento. Para tanto, farei um panorama sobre a dinamização dos estudos sobre letramento, em inter-relação com o que aponta alguns estudos sobre o uso dos gêneros orais em sala de aula de língua portuguesa na educação básica, segundo alguns estudos e os PCN.

Situado num contexto teórico considerado complexo, o termo letramento nos leva a mergulhar num universo que, com o passar dos anos, teve uma dinamização significativa em se tratando da leitura e da escrita em sala de aula. Sabendo que este deriva de um abrangente panorama histórico e sociocultural, tem-se que:

[...] em meados dos anos de 1980 que se dá, simultaneamente, a invenção do letramento no Brasil, do illettrisme, na França, da literacia, em Portugal, para nomear fenômenos distintos daquele denominado alfabetização, alphabétisation. Nos Estados Unidos e na Inglaterra, embora a palavra literacy já estivesse dicionarizada desde o final do século XIX, foi também nos anos de 1980 que o fenômeno que ela nomeia, distinto daquele que em língua inglesa se conhece como reading instruction, beginning literacy tornou-se foco de atenção e de discussão nas áreas da educação e da linguagem (SOARES, 2004, p. 6, grifos da autora).

No período que antecedeu os anos 80, o letramento (literacy) já vinha sendo estudado em universidades norte-americanas. Porém, no que concerne o seu modelo autônomo. A visão de letramento enquanto um conjunto de habilidades de leitura e 
REVISTA X, Curitiba, volume 13, n.2,p.34-46, 2018.

escrita em práticas sociais mediadas por relações de poder surge em 1984, através da importante pesquisa realizada pelo antropólogo Brian Street, no modelo de letramento ideológico. Além desse modelo, Street traz, também, o letramento autônomo, o qual compactua com o conceito estável de alfabetização enquanto capacidades de escrever e decifrar códigos linguísticos na escola. Dando especificidade aos estudos sobre letramento no Brasil, o que veio ocorrer com mais constância nos anos de 1990, por meio de pesquisas em Linguística (KLEIMAN, 2002) e em Educação (SOARES, 1996), muitas pesquisas começaram a abordar o termo em diversas perspectivas de estudo, principalmente quando a temática inicial tratava do ensino e da aprendizagem de línguas, muitas delas abordavam o letramento enquanto habilidade de uso da escrita, enquanto outras defendiam uma abrangência maior trabalhando, também, com a leitura.

Aqui, pensando em letramento pelo seu viés ideológico, entendo que ele possui um elo significativo com o emprego da oralidade em práticas escolares através do ensino de língua portuguesa, isso por considerar a linguagem enquanto prática social e, também, por entender que as relações de poder são mediadas, sobretudo, por meio da oralidade. Segundo os PCN, empregar a oralidade em sala de aula é "propor situações didáticas nas quais essas atividades façam sentido de fato, pois é descabido treinar um nível mais formal da fala, tomado como mais apropriado para todas as situações" (BRASIL, 1998, p. 25), essa questão desmistifica a ideia de que trabalhar com a oralidade na escola é a mesma coisa de ensinar o aluno a falar (LEAL \& GOIS, 2012).

As Orientações Curriculares para o Ensino Médio apontam que:

O que se prevê, portanto, é que o aluno tome a língua escrita e a oral, bem como outros sistemas semióticos, como objeto de ensino/estudo/aprendizagem, numa abordagem que envolva ora ações metalinguísticas (de descrição e reflexão sistemática sobre aspectos linguísticos), ora ações epilinguísticas (de reflexão sobre o uso de um dado recurso linguístico, no processo mesmo de enunciação e no interior da prática em que ele se dá), conforme o propósito e a natureza da investigação empreendida pelo aluno e pelos saberes a serem construídos (BRASIL, 2006, p. 33).

Visto isso, vale ressaltar que não objetivo apontar a oralidade e a escrita como as únicas modalidades de linguagem a serem trabalhadas em sala de aula, uma vez que os múltiplos sistemas semióticos que constituem a linguagem não-verbal são suficientemente interessantes para o desenvolvimento das práticas linguísticodiscursivas dos alunos. Além disso, é envolvendo as diversas modalidades de linguagem em sala de aula que os alunos serão levados a refletir criticamente sobre os contextos de 
REVISTA X, Curitiba, volume 13, n.2,p.34-46, 2018.

uso de cada uma delas. A oralidade, então, se faz como uma modalidade imprescindível, articulada com a escrita, para que exista uma relação harmônica entre as 'linguagens' nas práticas escolares da educação básica.

\section{LEVANDO A ORALIDADE PARA O ENSINO DE LÍNGUA PORTUGUESA}

Como venho discutindo no decorrer desse artigo, atrelar o ensino da linguagem em sala de aula com as questões emergentes da sociedade é, em grande escala, salutar para o desenvolvimento progressivo da aprendizagem e das práticas linguísticodiscursivas dos alunos, principalmente na educação básica brasileira que vem sendo o maior alvo dos estudos sobre ensino na Linguística Aplicada atual. Nessa perspectiva, nesse espaço discuto, por meio de duas atividades de letramento, as quais apliquei enquanto professor, com enfoque na oralidade, as possibilidades de se estudar os saberes locais e outros conteúdos no ensino de língua portuguesa com base no uso dos gêneros debate e conto, entendendo que a oralidade propicia a reflexão sobre as adequações nas diferentes situações comunicativas (MARCUSCHI, 1997).

\subsection{Atividade de reflexão sobre a diversidade linguística no município que vivem por meio do debate}

Em algumas aulas que ministrei em turma de $8^{\circ}$ ano do ensino fundamental numa escola de esfera pública do interior de Alagoas tive a obrigação de discutir com os alunos sobre a representação social ${ }^{7}$ da língua portuguesa no Brasil, isso porque muitos alunos tinham a crença de que por residirem num estado de alto nível de violência, onde poucas pessoas estudam e são qualificadas, a língua portuguesa falada por ele e pelos colegas é errada e que a correta era somente falada na região centro-sul do país. $\mathrm{Na}$ última turma, já nas vésperas das avaliações finais, resolvi propor uma atividade sobre essa questão, a qual, em linhas gerais, foi satisfatória.

Solicitei que os alunos observassem as palavras que consideravam 'erradas' utilizadas pelas pessoas que moram nas suas comunidades (ruas, avenidas, etc.) por uma semana, anotassem e trouxessem para que debatêssemos sobre o uso da língua portuguesa nessas localidades. Após uma semana os alunos vieram à sala com uma infinidade de palavras diferentes e iniciamos a atividade discutindo sobre o porquê de essas palavras serem erradas se quando pronunciadas todos as entendem. Muitos alunos

\footnotetext{
${ }^{7}$ Trato mais a fundo do conceito de representação social no ensino de língua portuguesa em $O$ letramento e sua representação social na formação docente em língua materna (SILVA JÚNIOR \& SILVA, 2016).
} 
REVISTA X, Curitiba, volume 13, n.2,p.34-46, 2018.

alegaram que no dicionário as palavras não são escritas daquela maneira e debateram entre si o que acontece quando alguém, ao invés de "porta" pronuncia "poitxa".

Nesse sentido, expliquei que existem variações linguísticas na língua portuguesa e que a nossa língua é um aspecto social que vive em constante mudança, e que além das localidades deles existem outras com mais uma infinidade de variações como esta. Seguimos então discutindo sobre os contextos sociais que requerem o uso de uma variação linguística com mais prestígio e os que não têm essa exigência.

Após o debate, solicitei que os alunos pensassem em casa sobre três termos, com mais de uma variação, e mencionassem três contextos sociais onde cada uma dessas variações poderia ser usada. E assim fizeram. Um dos termos mais interessantes que trouxeram foi "chinelo", onde a aluna assinalou que em casa pode se chamar "japonesa", na sorveteria "havaiana", já no banco "chinelo", pois no banco, além das pessoas simples e humildes, também é frequentado por profissionais da área jurídica e educacional, acostumados a usar a norma chamada padrão.

Diante disso, vê-se que o debate oral deu espaço para uma densa reflexão sobre as variações linguística por meio do contexto social em que os alunos vivem. Esse fato se dá pelo senso de pesquisa que os alunos têm e a vontade de correr atrás para conhecer mais a fundo as transformações sociais, nesse caso, da linguagem, através da escola. Para isso, é necessário que o professor reflita primeiramente sobre essa questão e elabore um plano estratégico para que a aula não se prenda muito ao estudo teórico das variações linguísticas, o que é de responsabilidade do curso de letras em contexto de formação de professores, e que se lance a estimular a oralidade dos alunos por meio dos gêneros orais como o debate, a mesa-redonda e entre outros.

\subsection{Criação de contos a partir do estudo das figuras de linguagem}

Desde a minha educação básica, cursada de 2002 a 2012, via as figuras de linguagem como um assunto interessante, porém, muito repleto de características semelhantes uma das outras, o que me deixava relativamente confuso. Quando comecei a atuar numa turma de $8^{\circ}$ ano no início do $3^{\circ}$ bimestre, me vi em uma situação complicada, tanto por não conhecer a turma como por não saber de quais recursos a escola portava naquele momento para auxiliar a minha prática pedagógica. Ao ter contato com o plano anual de ensino da escola, percebi que o próximo conteúdo a ser abordado seria as figuras de linguagem e, ali, comecei a pensar em como apresentar 
REVISTA X, Curitiba, volume 13, n.2,p.34-46, 2018.

todas àquelas figuras sem que aquilo parecesse monótono e chato. Foi quando vi a possibilidade de atrelar isso aos gêneros do discurso.

Não pude fugir, na primeira aula, da aula expositiva sobre as características do conto e das figuras de linguagem. Naquele momento não via alternativa diferente. Após dar alguns exemplos de orações que continham as figuras de linguagem trabalhadas na aula (metáfora, metonímia, catacrese, comparação e ironia) e ter lido junto com os alunos alguns contos encontrados na internet, lancei a proposta de produção de contos utilizando o conhecimento sobre as figuras de linguagem, com o diferencial de que os contos seriam relacionados aos lugares onde cada um vive, numa inter-relação com as práticas sociais. Logo recebi resposta positiva dos alunos e começamos a estruturar o conto, primeiramente, na escrita.

$\mathrm{Na}$ aula seguinte, um aluno trouxe uma parte do seu conto e nela já havia a presença de duas figuras de linguagem (comparação e metáfora) e falava das histórias que sua avó contava. E assim mais textos vinham surgindo. Após duas aulas dedicadas a produção dos contos, perguntei se os alunos conheciam bem o conto a ponto de poderem contá-los oralmente. Muitos ficaram receosos, mas prometeram tentar. A proposta, a primeira vista, pode parecer um processo de oralização de um texto escrito. No entanto, não se constitui dessa forma, justamente pelo fato de os alunos serem os reais produtores de texto e terem a possibilidade de contá-los de modo particular, até mesmo não linear. Não posso dizer, aqui, que todos tiveram coragem de contar, no entanto, a grande maioria da turma pediu para apresentar. Depois de cada performance, os alunos explicavam onde estavam às figuras de linguagem que utilizaram e como elas implicam na construção de sentidos dos seus textos.

Nessa experiência, pode-se perceber uma preocupação interessante em estimular o senso crítico dos alunos e explicá-los, na prática, que os assuntos abordados na escola fazem parte do cotidiano deles, isso é um ponto relevante até mesmo para os professores entenderem a dinamização do ensino de língua que, em linhas gerais, é um ensino de linguagem, de múltiplas linguagens. Vejo que seria salutar, também, em outro momento, expandir essa discussão e produzir textos multimodais com esses contos, o que traria à tona as modalidades de linguagem. O letramento, então, fica evidente do modo em que o conhecimento local se materializa na atividade em sala de aula, visto que o aluno é levado a identificar como o objeto de ensino faz diferença nas suas práticas linguístico-discursivas. 
REVISTA X, Curitiba, volume 13, n.2,p.34-46, 2018.

\section{CONSIDERAÇÕES FINAIS}

A principal característica que estimulou a escrita desse trabalho foi a observação que fiz na minha prática pedagógica, na qual constatei que teoria e prática não somente devem, mas andam juntas e ligadas intimamente no processo de ensino e de aprendizagem de língua portuguesa, desmistificando o discurso de que, na prática, teoria e prática andam muito afastadas. Ousando dizer que isso existe, também, em outros componentes da matriz curricular da educação básica.

Entender a linguagem em seu caráter dialógico, estabelecida pelo elo entre o discurso do eu com o outro faz com que o professor em serviço compreenda responsiva e ativamente (BAKHTIN, 2003) as relações sociais que permeiam a sua prática e como elas podem positivamente implicar na formação escolar e social dos alunos. Nesse sentido, é sempre interessante que as propostas prontas de atividades em materiais didáticos sejam de certa forma desobedecidas (ZOZZOLI, 2015), para que as atividades não sejam trabalhadas num ponto de vista sincrônico, mas sim, adepto às necessidades dos alunos.

Como conclusão, lembro que os professores dos dias atuais não podem situar-se numa postura estável e a espera de materiais que possam ditar regras para o que podem e devem fazer na prática. É preciso assumir uma postura de empoderamento e, acima de tudo, de autoconfiança do que é capaz de fazer para não transmitir, mas aprender coletivamente com os alunos que atribuem sentido ao seu trabalho.

\section{REFERÊNCIAS}

BAKHTIN, M. M. Estética da Criação Verbal. Tradução de Paulo Bezerra. São Paulo: Martins Fontes, 2003.

BAKHTIN, M. M. Marxismo e Filosofia da Linguagem. São Paulo: Martins Fontes, 2006.

BRASIL, SNEB. Orientações Curriculares para o Ensino Médio. Linguagens, códigos e suas tecnologias. Brasília: Ministério da Educação, 2006.

BRASIL, SNEB. Parâmetros Curriculares Nacionais: Língua Portuguesa. Brasília: MEC, 1998.

KLEIMAN, A. B. Alfabetização e letramento: implicações para o ensino. Revista da FACED, v. 6, p. 99-112, 2002. 
REVISTA X, Curitiba, volume 13, n.2,p.34-46, 2018.

KOCH, I. V. O texto e a construção dos sentidos. 8.ed. São Paulo: Contexto, 2005.

LEAL, T. F; GOIS, S. (Orgs). A oralidade na escola: a investigação do trabalho docente como foco de reflexão. Belo horizonte: Autêntica Editora, 2012.

MARCUSCHI, L. A. Concepção de língua falada nos manuais de português de $1^{o}$ e $2^{o}$ graus: uma visão crítica. 49a Reunião Anual da SBPC. Belo Horizonte, julho de 1997.

MARCUSCHI, L. A. Da fala para a escrita: atividades de retextualização. São Paulo: Cortez, 2001.

MARCUSCHI, L. A; DIONÍSIO, A. P. Fala e escrita. Belo Horizonte: Autêntica, 2007.

MOITA LOPES, L. P (Org.) Por uma linguística aplicada indisciplinar. São Paulo: Parábola, 2006.

POSSENTI, S. Por que (não) Ensinar Gramática na Escola. Campinas, SP: Mercado de Letras, 1996.

SILVA JÚNIOR, S. N; SILVA, E. B. O letramento e sua representação social na formação docente em língua materna. REVEXT - Revista de Extensão da Universidade Estadual de Alagoas - UNEAL, v. 2, p. 149-165, 2016.

SOARES, M. Letramento e alfabetização: as muitas facetas. Revista Brasileira de Educação, n. 25, 2004.

SOARES, M. B. Letramento/Alfabetismo. Presença Pedagógica, Belo Horizonte, v. 2, n.10, p. 83-89, 1996.

STREET, B. V. Literacy in theory and practice. Cambridge: Cambridge University Press, 1984.

ZOZZOLI, R. M. D. Conhecimentos linguístico - discursivos na sala de aula de língua portuguesa: desenvolvendo táticas para desobedecer a propostas prontas. Revista Leia Escola, v. 14, p. 40-50, 2015.

ZOZZOLI, R. M. D. Relações entre pesquisa universitária e sociedade: leitura, produção e professor pesquisador. Linguagem \& Ensino (UCPel. Impresso), v. 13, p. 121-138, 2010. 